\title{
Effect of Steel Cord Tension During the Lapping on Steel Cord Straightness After Lapping
}

\author{
Marcin Knapinski \\ Czestochowa University of Technology, Poland \\ Yuri L. Bobarikin, Yuri. V. Martyanov \\ P.O. Sukhoi State Technical University of Gomel, \\ Republic of Belarus
}

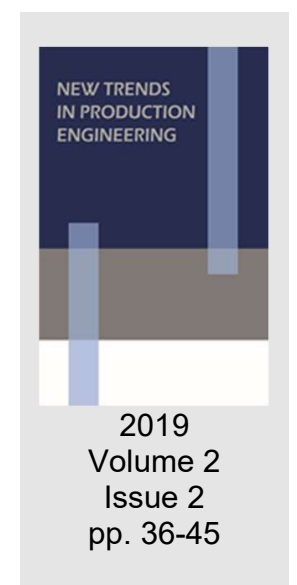

Date of submission to the Editor: 09/2019

Date of acceptance by the Editor: 11/2019

\section{INTRODUCTION}

Steel cord is used to produce automobile tires, rubber belts, strands, construction components for building and others (Girskas \& Nagrockienè, 2016, Gattesco et al., 2015, Bely \& Goncharenko, 1971, Sukhorukov et al., 2013). Increasing the straightness of the steel cord is an important task for modern science. High straightness of the steel cord is an important regulated technological property that depends on many factors, such a drawing speed, twisting speed, steel microstructure, chemical composition and others (Wei et al., 2019, Fedorko et al., 2016 Wang et al., 2019, Kapp et al., 2016, Matsumoto et al., 2018). For automatic lines, that uses steel cord as a raw material, an increased deviation from the straightness of the steel cord leads to a decrease in productivity and a decrease in the quality of the finished product.

Steel cord is produced by twisting the individual wires on a cable machine into a single strand. Steel cord is predominantly manufactured on double-twist cable machines by successive twisting of thin, brass-plated carbon and high carbon steel wire. As a result of the steel cord twist, the wire forms a volumetric spiral. The technology of twisting determines the construction of the steel cord. In the process of twisting the wire undergoes torsional and tensile stresses.

Steel cord is always under automatic control during its production. There are some methods of steel cord properties control in final product such a tires, strands, ropes: magnetic sensors, bidirectional bending, one axis twisting and others (Blazhej et al., 2018, Kruzel \& Ulewicz, 2019, Kozłowski et al., 2019).

After twisting, the steel cord undergoes preparatory operations in the lapping unit of the cable machine. To reduce the level of internal residual stresses in the steel cord during its production and lapping on the reel, deformer roller are used (deformers, flattening devices) installed in cable machines in the steel cord lapping unit (Sukhorukov et al., 2013). Early studies have shown that the use of deforming devices reduces the level of internal residual stresses and is an 
effective way to increase the straightness of the steel cord (Bobarikin et al., 2015).

One of the variable parameters of the steel cord manufacturing process is the magnitude of the tension of the steel cord before it is wound onto the receiving reel. This parameter is easily configured without significant changes in the general steel cord production technology and can be changed without stopping the equipment. The second variable parameter in the study adopted the diameter of the deformer roller. Setting this parameter requires stopping the equipment and replacing the deformer assembly.

Objective: to determine the effect of the tension of the steel cord before it is wound on the receiving reel on the straightness of the steel cord.

\section{METHODOLOGY OF RESEARCH}

Now there are several methods of analytical calculation of technological and mechanical characteristics of wire and steel cord, which are described in (Vedenee et al., 2000, Bely \& Goncharenko, 1971). The essence of the techniques lies in the analysis of the displacement of the fibers of the wire when twisting the steel cord and obtaining the numerical values of the yield strength of the wire, the degree of hardening of the wire during the twisting, twisting and bending moment. The geometric characteristics of the steel cord are derived from the condition of touching the ellipses.

Despite the availability of calculation methods and various approaches, the available calculation options do not provide an accurate result for relatively large deformations of the wire. As is known, various steel cord designs, as well as stranding methods, require an individual approach, and, therefore, analytical methods will not always be suitable for calculations, since it is impossible to unify them.

The main method of research: numerical modeling of a steel cord bend on a deforming roller, criteria qualitative assessment of results.

One of the methods for numerical simulation of processes is the finite element method (Sukhorukov et al., 2013). Modern software packages are used for analysis. The numerical simulation based on the finite element method makes it possible to obtain an overall picture of the stresses and strains of the wire in the process of rolling into the steel cord with high accuracy of calculations. With this approach, calculations should be carried out using a computer. The main tasks in numerical simulation is the correct construction of the model from the point of view of geometry, as well as the selection of the optimal type of finite element mesh. The accuracy and duration of the calculations, as well as the adequacy of the model constructed, will depend on the chosen type of the final element, its geometric shape. It is also important to correctly define and set the boundary conditions of the model. In the process of calculating the process, the distortion of the geometric dimensions of the final element of more than $30 \%$ is unacceptable. This can be achieved by placing the grid elements along the wire axis and parallel to each other. This grid construction feature was presented in (Kalent'yev \& Tarasov, 2010). Other examples of mesh construction and model 
definition were presented in (Jin et al., 2009, Gattesco et al., 2015, Korunović et al., 2019).

After selecting the type of finite element of the mesh and its construction, internal and external influences are specified boundary and initial conditions, such as the initial temperature of the wire, the material of the wires, the coefficient of contact and internal friction, the strain rate (twisting) and other aspects, the direction and speed of twisting of the wire.

Numerical simulation with a sufficient level of adequacy of the model makes it possible to conduct numerical experiments relatively quickly compared to a fullscale experiment. An additional advantage of numerical simulation over the experiment is the ability to wide the ranges of changes of the studied factors. When conducting full-scale experimental studies, it is rather difficult to ensure that the conditions of the experiment are identical. This is due to the high chance of error that external factors have that affect the results of the experiment. In addition, the difficulty consists in limiting the increase in the number of variable parameters and the range of their change due to a significant increase in the number of experiments in the experiment.

Numerical modeling involves the simplification of some factors, the adoption of individual quantities by infinitesimally, as well as the presence of initial and boundary conditions.

In the numerical experiment, the following main hypotheses were adopted:

1 The continuity hypothesis: the material continuously fills the entire volume of the body. This hypothesis allows one to apply the analysis of infinitely small quantities and not to take into account the molecular, crystalline structure of matter;

2 Homogeneity hypothesis: material properties are the same at all points of the body;

3 Hypothesis of isotropy: material properties do not depend on direction.

The study also made assumptions: the body of the roller is smooth in terms of geometry, that is, the cylinder has no defects and discontinuities. The AmontonCoulomb friction law in terms of the friction coefficient describes the contact interaction between the wires. The friction coefficient is assumed constant and equal to 0.15. Input data are presented in Table 1.

Table 1 Model input for numerical experimen
\begin{tabular}{|l|c|}
\hline \multicolumn{1}{|c|}{ Name of the parameter } & Value \\
\hline Steel cord construction & $2 \times 0.30 \mathrm{HT}$ \\
\hline Number of wires & 2 \\
\hline Wire diameter & $0.30 \mathrm{~mm}$ \\
\hline Max. tensile stress & $3000 \mathrm{MPa}$ \\
\hline Type of cord construction & closed \\
\hline Lenth of one cord step & $14 \mathrm{~mm}$ \\
\hline Tension device type & string \\
\hline Tension direction & $\pm Z$ \\
\hline
\end{tabular}

The photo and the scheme of the investigated unit are presented in Figure 1 and 2 


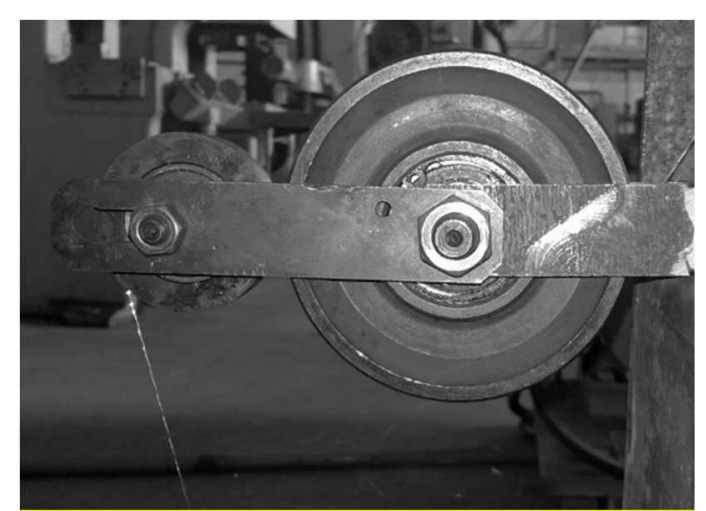

Fig. 1 Photo of the deforming unit

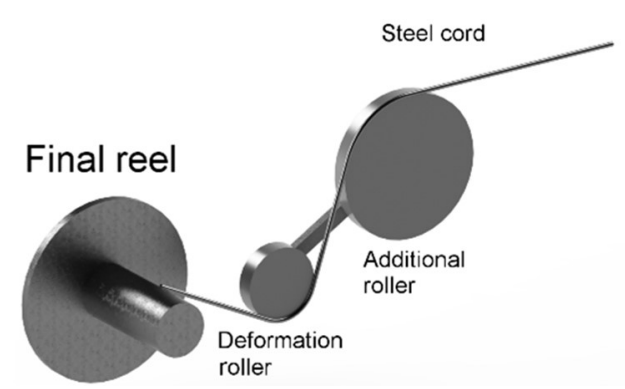

Fig. 2 Scheme of the deforming unit

The output parameters of the numerical model are the equivalent active stresses in the steel cord during bending and the average displacements of the nodes of the finite element grid at the places where the wires overlap each other.

For the numerical experiment, the boundaries of the study were taken. For roller diameter varies from 20 to $80 \mathrm{~mm}$. The following values are used for tension: $9 \mathrm{H}, 11 \mathrm{H}, 16 \mathrm{H}, 25 \mathrm{H}, 30 \mathrm{H}$.

The plan of the numerical experiment is constructed along the chosen boundaries. The plan of the numerical experiment is presented in Table 2.

Table 2 Numerical experiment plan Roller diam
\begin{tabular}{|c|c|c|c|}
\hline $20 / 11$ & $20 / 16$ & $20 / 25$ & $20 / 30$ \\
\hline $30 / 11$ & $30 / 16$ & $30 / 25$ & $30 / 30$ \\
\hline $40 / 11$ & $40 / 16$ & $40 / 25$ & $40 / 30$ \\
\hline $50 / 11$ & $50 / 16$ & $50 / 25$ & $50 / 30$ \\
\hline $60 / 11$ & $60 / 16$ & $60 / 25$ & $60 / 30$ \\
\hline $70 / 11$ & $70 / 16$ & $70 / 25$ & $70 / 30$ \\
\hline $80 / 11$ & $80 / 16$ & $80 / 25$ & $80 / 30$ \\
\hline
\end{tabular}

To analyze the data obtained, a criterion approach is used with the criterion for the qualitative assessment of the straightness of the steel cord (Bobarikin et al., 2019). The main advantage of criterion assessment is the possibility of an integrated approach to measurement, evaluation and decision-making only based on the input data of the system. On the example of steel cord production, this means that it is possible to qualitatively evaluate the indicators of the finished product before its production and release by quantitative indicators of the technological process.

The approach according to which the complex criterion of a qualitative assessment of the straightness of the steel cord using a deformer is calculated 
(Bobarikin \& Martyanov, 2016). The value of the criterion when choosing a deforming roller deformer should be minimal. Fulfillment of this condition provides the minimum gradient. Displacements of the nodes of the finite element mesh at the places where the wires are laid.

Consequently, the stability of the process of changing the contact interaction between the wires and the changes in stress arising during bending is increased. Stability is understood as a phenomenon in which the value of axial displacements and stresses is maintained with a change in the diameter of the deforming roller. The stability of the axial displacement of the wires will ensure maximum uniformity of contact interactions between the wires in the steel cord. The high uniformity of contact interactions in the steel cord helps to reduce the level of relaxation of residual stresses and residual deformations, which cause deviations of the steel cord from straightness. The displacement of contact points and the change in contact interaction depends on the axial shift of the wires in the steel cord during bending (Bobarikin \& Martjanov, 2019).

\section{RESULTS}

The results of the numerical experiment are presented in the form of color-coded diagrams of the effective stresses in the steel cord, and displacements in the \pm $Z$ direction.

Table 3 presents the effective (effective total) voltage of the steel cord.

Table 3 Effective (effective total) stresses of the steel cord, MPa

\begin{tabular}{|c|c|c|c|c|c|}
\hline Diameter of the deforming roller, & \multicolumn{5}{|c|}{ Tension, N } \\
\cline { 2 - 5 } $\mathbf{m m}$ & $\mathbf{9}$ & $\mathbf{1 1}$ & $\mathbf{1 6}$ & $\mathbf{2 5}$ & $\mathbf{3 0}$ \\
\hline 20 & 171 & 170 & 201 & 267 & 275 \\
\hline 30 & 144 & 143 & 175 & 240 & 251 \\
\hline 40 & 148 & 150 & 172 & 212 & 237 \\
\hline 50 & 122 & 159 & 201 & 236 & 239 \\
\hline 60 & 141 & 143 & 191 & 216 & 239 \\
\hline 70 & 143 & 143 & 179 & 190 & 239 \\
\hline 80 & 143 & 143 & 187 & 191 & 203 \\
\hline
\end{tabular}

Table 4 shows the movement of the nodes of the grid of finite elements of the steel cord in the axial direction.

Table 4 Movement of the finite element end points of the steel cord in the axial direction, $\mathrm{mm}$

\begin{tabular}{|c|c|c|c|c|c|}
\hline Diameter of the deforming roller, & \multicolumn{5}{|c|}{ Tension, N } \\
\cline { 2 - 5 } $\mathbf{m m}$ & $\mathbf{9}$ & $\mathbf{1 1}$ & $\mathbf{1 6}$ & $\mathbf{2 5}$ & $\mathbf{3 0}$ \\
\hline 20 & 0,24 & 0,026 & 0,158 & 0,185 & 0,133 \\
\hline 30 & 0,128 & 0,057 & 0,08 & 0,144 & 0,099 \\
\hline 40 & 0,055 & 0,044 & 0,051 & 0,114 & 0,161 \\
\hline 50 & 0,116 & 0,103 & 0,1 & 0,154 & 0,146 \\
\hline 60 & 0,086 & 0,025 & 0,047 & 0,122 & 0,251 \\
\hline 70 & 0,132 & 0,048 & 0,043 & 0,172 & 0,244 \\
\hline 80 & 0,064 & 0,015 & 0,055 & 0,028 & 0,053 \\
\hline
\end{tabular}

For ease of understanding, the interpretation was made in a three-dimensional graph-field. Interpretation results are presented in Figure 3 and 4. 


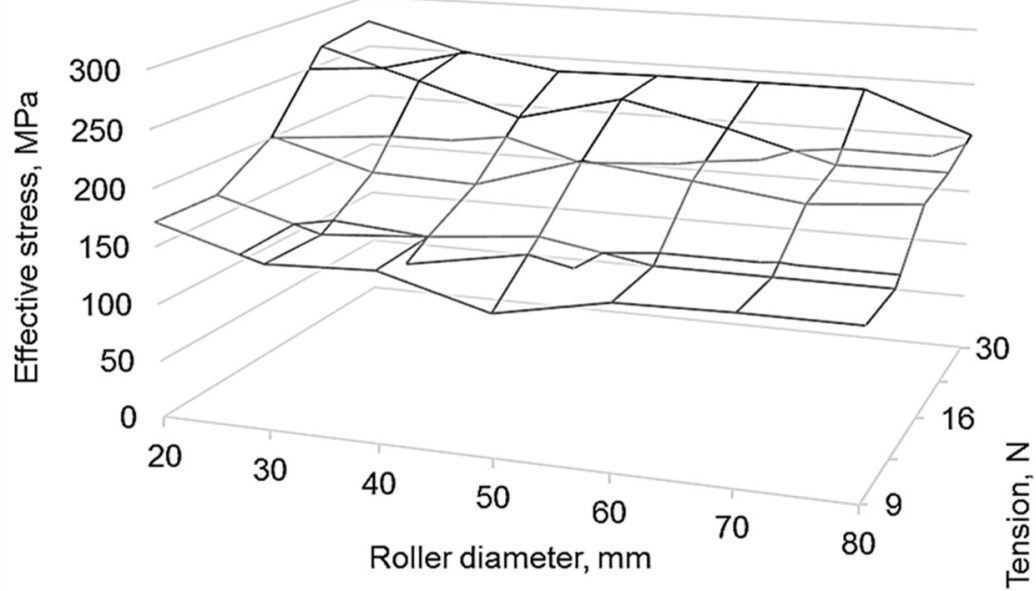

Fig. 3 The field of dependence of stress on the diameter of the roller and the tension

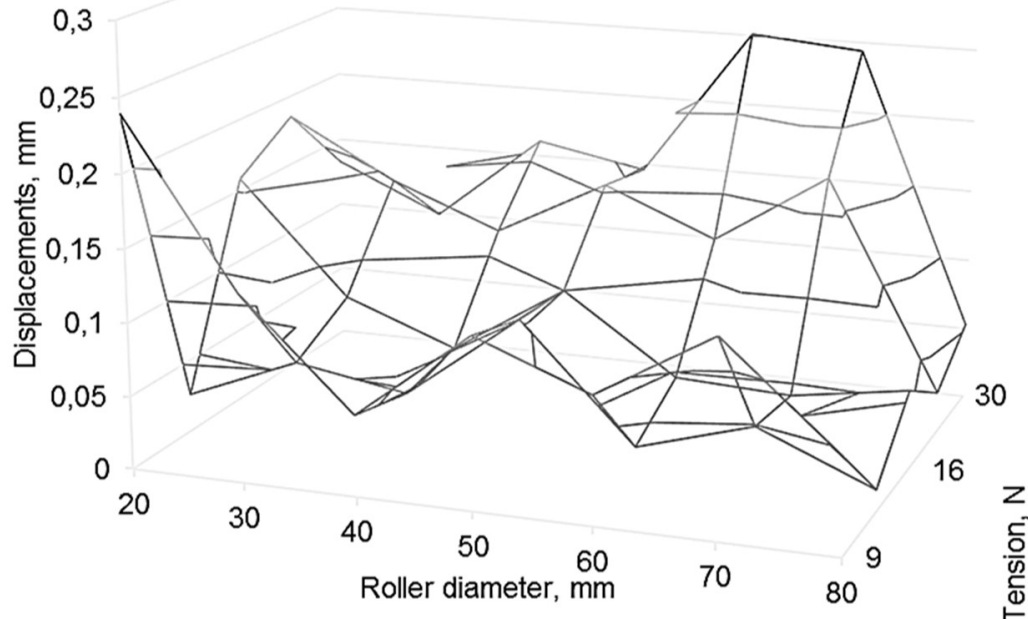

Fig. 4 The field of displacement depending on the diameter of the roller and tension

The straightforwardness of the steel cord $2 \times 0.30 \mathrm{HT}$ was evaluated using a complex criterion for qualitative assessment.

The color-coded diagrams from the numerical experiment according to the plan were transformed into a numerical form and are presented in Table 5 as the values of the complex criterion for the qualitative assessment of the straightness of the steel cord. The values of criterion is shown in Table 5.

Table 5 The results of numerical simulation in the form of a comprehensive quality assessment criterion values straightness of steel cord

\begin{tabular}{|c|c|c|c|c|c|c|c|c|}
\hline \multicolumn{2}{|c|}{ Roller diameter, $\mathbf{m m}$} & $\mathbf{2 0}$ & $\mathbf{3 0}$ & $\mathbf{4 0}$ & $\mathbf{5 0}$ & $\mathbf{6 0}$ & $\mathbf{7 0}$ & $\mathbf{8 0}$ \\
\hline \multirow{4}{*}{ Tension, N } & 9 & 118,18 & 49,27 & 57,10 & 27,09 & 30,19 & 53,51 & 51,52 \\
\cline { 2 - 9 } & 11 & 68,02 & 120,28 & 23,33 & 38,33 & 76,39 & 92,00 & 68,75 \\
\cline { 2 - 9 } & 16 & 75,65 & 51,03 & 36,29 & 18,95 & 53,23 & 10,58 & 28,26 \\
\cline { 2 - 9 } & 25 & 58,16 & 24,36 & 23,88 & 49,54 & 22,44 & 42,71 & 83,72 \\
\cline { 2 - 9 } & 30 & 11,28 & 27,01 & 62,87 & 10,36 & 71,92 & 2,79 & 79,71 \\
\hline
\end{tabular}

The distribution of the criterion value depending on the selected roller / tension mode is shown in Figure 5. 


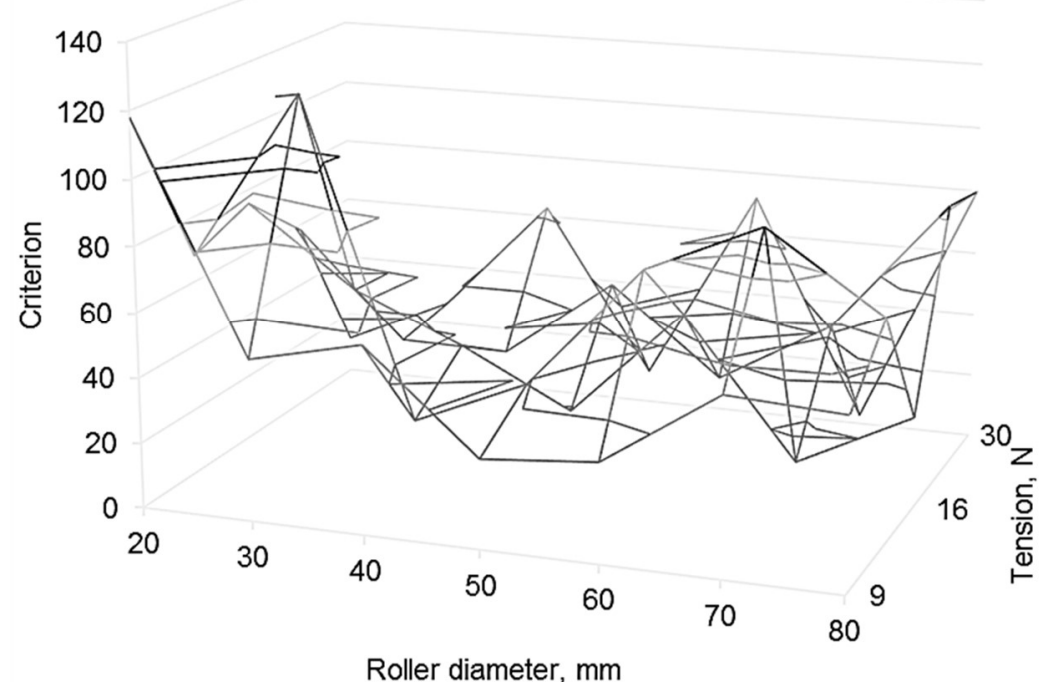

Fig. 5 Distribution of the criterion value depending on the selected roller/tension mode

According to Figures 3-5 it is possible to analyze the distribution of stresses and displacements in the construction of a steel cord depending on the tension and diameter of the deforming roller.

\section{DISCUSSION}

In the process of steel cord lapping, tensile, twisting and bending stresses and strains act on the wire. Equivalent deformation is the reduced deformation to estimate the total deformation effect on the wire when twisted in the cable machine. For the stranding paths, zones of large deformations of the wire are provided compared to the other zones of the cable machine. In such zones, the steps of lapping the wires into the steel cord are performed, and the wires can be deformed in various directions. However, in absolute terms, the total equivalent strain always increases. The diameter of the steel cord, aggregate strength, adhesion force with rubber depend on the wires and their location in the steel cord.

Non-twisting of the steel cord is provided by additional twisting of the strand in the torsion device to achieve deformation wires in the plastic region. After additional twisting, the pitch of the steel cord is slightly increased and further unwinds in the opposite direction in the area of elastic deformations. The magnitude of the additional twisting of the steel cord is created by the rotation frequency of the torsion device.

According to Figure 3 , it is possible to determine the stress extremes, their location. This provides information on the effect of variable parameters on the effective stresses in the steel cord. Maximum stresses are achieved with a roller diameter of $10 \mathrm{~mm}$ and a tension of $30 \mathrm{~N}$. The optimum voltage change is in the range of a roller diameter from 40 to $60 \mathrm{~mm}$ and a tension of $25 \mathrm{~N}$.

According to Figure 4, it is possible to determine the extremes of displacements. Dependence is implicit and generally non-linear. According to the current sample of results, it can be determined that the possible optimal mode is in the intervals of the roller diameter from 30 to $50 \mathrm{~mm}$ and tension from 11 to $16 \mathrm{~N}$. 
According to Figure 5 it is possible to determine the optimal settings for the process of manufacturing the steel cord when adjusting the parameters of the tension and the diameter of the roller. According to the provisions of the adopted criteria evaluation, the optimal adjustment mode is in the range of the roller diameter from 40 to $50 \mathrm{~mm}$ and with tension from 16 to $25 \mathrm{~N}$. There are separate points on the graph, which can also mean that there is an optimal mode for setting up the process. These points require additional study.

\section{CONCLUSION}

The study obtained the following results:

1 the effect of the tension of the steel cord and its bend radius in the deformer on the stresses and displacements in the steel cord is determined;

2 with an increase in tension and a decrease in the diameter of the deforming roller, the effective stresses in the steel cord increase;

3 with increasing tension, axial displacements increase;

4 with an increase in the diameter of the deforming roller, the displacement of $Z$ as a whole decreases, a periodic wavy dependence of the decrease is observed;

5 the effect of stresses and displacements in the steel cord on the straightness of the steel cord after bending was determined using the criteria-based method for the qualitative assessment of the straightness of the steel cord;

6 by adjusting the tension and diameter of the deforming roller, it is possible to adjust the optimum technological mode of winding of the steel cord to the receiving coil to ensure minimal deviation from straightness;

For further research in the field of the influence of the tension of the steel cord before winding on its straightness, it is required to expand the studied range of tension values. The upper tension value is limited by the constructive capability of the cable machine. The lower value is limited by the need to obtain the required filing density and ensure the non-twistability of the steel cord. This requirement is assigned to each steel cord construction individually.

\section{REFERENCES}

Bely, V. D. and Goncharenko N. K. (1971), Issledovaniye NDS kanatov seriynogo izgotovleniya posle predvaritel'noy deformatsii [SSS research of serial production ropes after preliminary deformation] «Stal'nyye kanaty», vol. 8 - K., Tekhnika. p. 310 ;

Blazhej, R. Jurdziak, L. Kozlowski, T. Kirjanow A. (2018), The use of magnetic sensors in monitoring the condition of the core in steel cord conveyor belts. Tests of the measuring probe and the design of the DiagBelt system, Measurement, Volume 123, pp. 48-53;

Bobarikin, Yu. L. and Martjanov Yu. V. (2019), Vliyaniye parametrov deformatsii metallokorda pered namotkoy na yego pryamolineynost' posle namotki [Effect of deformation parameters of a steel cord before winding on its straightness after winding] Vestnik GGTU n.a. P. O. Sukhoi. - 2019. - №1. - p. 50-55.

Bobarikin, Yu. L. and Martyanov Yu. V. (2016), Vliyaniye diametra deformiruyushchego rolika na makroperemeshcheniya $v$ metallokorde [Influence of the diameter of a deforming roller on macroscopic displacement in a steel cord] Modern problems of mechanical engineering: mes. Report XI Intern. Scientific-tech. Conf. (scientific 
reading, dedicated to P. O. Sukhoi), Gomel, Oct. 20-21. 2016 M-education Resp. Belarus, GSTU n.a. P. O. Sukhoi, a branch of PJSC "Company" Sukhoi "OKB" Sukhoi"; under total Ed. S.I. Timoshin. - Gomel: GSTU n.a. P. O. Sukhoi, 2016. p. $117-118$

Bobarikin, Yu. L. Avseykov, S. V. Martyanov, Yu. V. Vedeneyev A. V. (2015), Opredeleniye diametra rolika obratnoy deformatsii dlya kanatnoy mashiny $v$ uzle namota metallokorda [Determination of the diameter of the deformation roller for the reverse deformation in cable machine at the place of steel cord winding] ISSN 2076-2151. Obrabotka materialov davleniyem. № 1 (40); (in Russian);

Bobarikin, Yu. L. Martyanov, Yu. V. and Vedeneyev A. V. (2019), Vliyaniye natyazheniya metallokorda pri namotke na yego pryamolineynost' [The effect of the tension of the steel cord during winding on its straightness] Chernye metally. 2019. No. 4. pp. 46-50.

Bobarikin, Yu.L. Martyanov, Yu.V. Vedeneyev A.V. (2017), Effect of deformation parameters. XVIII International scientific conference "New technologies and achievements in metallurgy, production engineering and physics" A collective monograph edited by J. Borica, D. Musial: monograph No. 68, Chestohowa (Poland).- p. 133-141;

Fedorko, G. Molnár, V. Ferková Ž., Peterka, P. Krešák, J. Tomašková M. (2016), Possibilities of failure analysis for steel cord conveyor belts using knowledge obtained from non-destructive testing of steel rop es. Engineering Failure Analysis, Volume 67, pp. 33-45;

Gattesco, N. Amadio, C. and Bedon C. (2015). "Experimental and numerical study on the shear behaviour of stone masonry walls strengthened with GFRP reinforced mortar coating and steel-cord reinforced repointing", Engineering Structures, 90(5): pp. 143-157;

Girskas, G. and Nagrockienè D. (2016), The Use of Steel Cord Scrap in Concrete, Construction Science, Vol. 18, pp. 22-26.

Jin, G. Liu, Y. Liu W. (2009), Spin squeezing in a generalized one-axis twisting model, International Journal of Theoretical Physics, Vol. 58, Issue 8, pp. 2414-2417;

Kalent'yev, Ye. A. and Tarasov V. V. (2010), Chislennyy analiz NDS ka-nata s lineynym kasaniyem pri rastyazhenii i kruchenii, Institut prikladnoy mekhaniki [Numerical analysis of the SSS of a strand with linear tangency under tension and torsion]. Institute of Applied Mechanics, Ural Branch of the Russian Academy of Sciences, Izhevsk, Russia, 2010. - pp.16-28;

Kapp, M.W. Hohenwarter, A. Wurster, S. Yang, B. Pippan R. (2016), Anisotropic deformation characteristics of an ultrafine- and nanolamellar pearlitic steel, Acta Materialia, Vol. 106, pp. 239-248;

Korunović, N. Fragassa, C. Marinković, D. Vitković, N. Trajanović M. (2019), Performance evaluation of cord material models applied to structural analysis of tires. Composite Structures, Volume 224; pp. 1-13;

Kozłowski, T. Błażej, R. Jurdziak, L. Kirjanów-Błażej A. (2019), Magnetic methods in monitoring changes of the technical condition of splices in steel cord conveyor belts. Engineering Failure Analysis, Volume 104, pp. 462-470;

Kruzel, R. and Ulewicz M. (2019), The fatigue strength of bidirectionally bent steel cord used in tires, Engineering Failure Analysis, Vol. 105, pp. 176-181;

Matsumoto, Yu. Miyashita, T. Takai K. (2018), Hydrogen behavior in high strength steels during various stress applications corresponding to different hydrogen embrittlement testing methods, Materials Science and Engineering: A, Vol. 735, pp. 61-72;

Sukhorukov, V.V. Vorontsov, A.N. Volokhovskiy V.Yu. (2013), Control of hoisting rope wear for hot metal cranes of metallurgical enterprises. Chernye metally. No. 10. pp. 56-60.

Vedenee, A. V. Zheltkov, A.S. Filippov, V. (2000), Analiz deformatsiy elementov vitykh struktur i ikh vliyaniye na poteri prochnosti pri proizvodstve metallokorda [Analysis of the deformations of elements of twisted structures and their effect on the loss of 
strength in the production of steel cord] News of the National Academy of Sciences of Belarus. M3. pp. 23-27;

Wang, L. Xue, Z. Zhu, H. Lei J. (2019), Thermodynamic analysis of precipitation behavior of Ti-bearing inclusions in SWRH 92A tire cord steel, Results in Physics, Volume 14, pp. 1-7;

Wei, D. Min, L. Li, X. Fang, F. Xie, Z. Jiang J. (2019), Microstructure and mechanical properties of heavily cold drawn pearlitic steel wires: Effects of low temperature annealing, Materials Characterization, Vol. 153, pp. 108-114.

\begin{abstract}
.
One of the variable parameters in steel cord twisting technologies is the steel cord tension before final reel. Changing this parameter is used to produce steel cord with high quality of straightness. Steel cord straightness is the most important technological parameter after tensile strength. It is simple to change the value of steel cord tension with special mechanisms or devices in composition of cable machines and twisting machines. It is very important to know the measures of tension setting. Low tension causes bad quality of steel cord and defects. High tension may brake steel cord during the twisting and lapping. Also high tension may change the mechanical properties of steel wire in the steel cord construction. The influence of steel cord tension in the range from $9 \mathrm{~N}$ to $30 \mathrm{~N}$ on active equivalent stresses in wire cross section and macro displacements of wire contact points in steel cord construction was shown. Effect of steel cord tension during the lapping on steel cord straightness after lapping was shown. In this research the optimal tension for producing steel cord $2 \times 0.30 \mathrm{HT}$ was defined with numerical simulation, finite element analysis and criteria method. The optimal value of tension for other steel cord constructions will change, because of number of wires and its hardness.
\end{abstract}

Keywords: cord, stresses, tension, straightness, macro displacements 